\title{
STABILITY OF A GENERALIZED JENSEN EQUATION ON RESTRICTED DOMAINS
}

\author{
S.-M. Jung, M. S. Moslehian And P. K. SAhoo
}

Abstract. In this paper, we establish the conditional stability of the generalized Jensen functional equation $f(a x+b y)=a g(x)+b h(y)$ on various restricted domains such as inside balls, outside balls, and punctured spaces. In addition, we prove the orthogonal stability of this equation and study orthogonally generalized Jensen mappings on balls in inner product spaces.

Mathematics subject classification (2010): Primary 39B82; Secondary 39B52, 39 B55.

Keywords and phrases: stability, Jensen's functional equation, orthogonally Jensen equation, orthogonality space, asymptotic behavior, punctured space.

\section{REFERENCES}

[1] T. AOKI, On the stability of the linear transformationin Banach spaces, J. Math. Soc. Japan, 2 (1950), 64-66.

[2] D.-H. Boo, S.-Q. OH, C.-G. PARK AND J.-M. PARK, Generalized Jensen's equations in Banach modules over a $C^{*}$-algebra and its unitary group, Taiwanese J. Math., 7 (2003), 641-655.

[3] D. G. Bourgin, Classes of transformations and bordering transformations, Bull. Amer. Math. Soc., 57 (1951), 223-237.

[4] L. CĂDARIU AND V. RADU, Fixed points and the stability of Jensen's functional equation, J. Inequal. Pure Appl. Math., 4 (2003), article 4, 7 pp.

[5] S. Czerwik, Functional Equations and Inequalities in Several Variables, World Scientific, River Edge, NJ, 2002.

[6] G. L. FORTI, An existence and stability theorem for a class of functional equations, Stochastica, 4 (1980), 23-30.

[7] G. L. ForTI, Hyers-Ulam stability of functional equations in several variables, Aequationes Math., 50 (1995), 143-190.

[8] P. GĂVRUTA, A generalization of the Hyers-Ulam-Rassias stability of approximately additive mappings, J. Math. Anal. Appl., 184 (1994), 431-436.

[9] D. H. HyERs, On the stability of the linear functional equation, Proc. Nat. Acad. Sci. U.S.A., 27 (1941), 222-224.

[10] D. H. Hyers, G. Is AC AND TH. M. Rassias, Stability of Functional Equations in Several Variables, Birkhäuser, Basel, 1998.

[11] D. H. Hyers AND TH. M. Rassias, Approximate homomorphisms, Aequationes Math., 44 (1992), $125-153$.

[12] D. H. Hyers, G. IS AC AND TH. M. RASSIAS, On the asymptoticity aspect of Hyers-Ulam stability of mappings, Proc. Amer. Math. Soc., 126 (1998), 425-430.

[13] W. JIAN, Some further generalizations of the Hyers-Ulam-Rassias stability of functional equations, J. Math. Anal. Appl., 263 (2001), 406-423.

[14] K.-W. Jun, D.-S. SHIN AND B.-D. KIM, Hyers-Ulam-Rassias stability of the Pexider equation, J. Math. Anal. Appl., 239, 1 (1999), 20-29.

[15] S.-M. JUnG, Hyers-Ulam-Rassias stability of Jensen's equation and its application, Proc. Amer. Math. Soc., 126 (1998), 3137-3143.

[16] S.-M. Jung, Stability of the quadratic equation of Pexider type, Abh. Math. Sem. Univ. Hamburg, 70 (2000), 175-190. 
[17] S.-M. Jung, Hyers-Ulam-Rassias Stability of Functional Equations in Mathematical Analysis, Hadronic Press, 2001.

[18] S.-M. Jung AND P. K. SAhoo, Hyers-Ulam stability of the quadratic equation of Pexider type, J. Korean Math. Soc., 38 (2001), 645-656.

[19] Z. Kominek, On a local stability of the Jensen functional equation, Demonstratio Math., 22 (1989), 499-507.

[20] Y.-H. LeE AND K.-W. JUn, A generalization of the Hyers-Ulam-Rassias stability of Jensen's equation, J. Math. Anal. Appl., 238 (1999), 305-315.

[21] M. S. Moslehian, On the stability of the orthogonal Pexiderized Cauchy equation, J. Math. Anal. Appl., 318, 1 (2006), 211-223.

[22] M. S. Moslehian AND L. SZÉKelYhidi, Stability of ternary homomorphisms via generalized Jensen equation, Results in Math., 49 (2006), 289-300.

[23] J. C. Parnami and H. L. Vasudeva, On Jensen's functional equation, Aequationes Math., 43 (1992), 211-218.

[24] J. M. RASSIAS AND M. J. RASSiAs, On the Ulam stability of Jensen and Jensen type mappings on restricted domains, J. Math. Anal. Appl., 281, 2 (2003), 516-524.

[25] TH. M. Rassias, On the stability of the linear mapping in Banach spaces, Proc. Amer. Math. Soc., 72 (1978), 297-300.

[26] TH. M. Rassias (ED.), Functional Equations, Inequalities and Applications, Kluwer Academic Publishers, Dordrecht, Boston, London, 2003.

[27] J. RÄTZ, On orthogonally additive mappings, Aequationes Math., 28 (1985), 35-49.

[28] J. SiKorSKA, Orthogonal stability of the Cauchy functional equation on balls in normed linear spaces, Demonstratio Math., 37 (2004), 579-596.

[29] F. S KOF, Sull'approssimazione delle applicazioni localmente $\delta$-additive, Atti Accad. Sci. Torino, 117 (1983), 377-389.

[30] S. M. Ulam, Problems in Modern Mathematics, Chapter VI, Science Editions, Wiley, New York, 1964. 